\title{
Obstructive sleep apnoea: a diabetologist's perspective
}

\author{
ABD A TAHRANI
}

\begin{abstract}
Obstructive sleep apnoea (OSA) is very common in patients with type 2 diabetes (T2D), which is unsurprising given that obesity is a major risk factor for both conditions. OSA has been associated with impaired quality of life, many cardiovascular disease (CVD) risk factors and cardiovascular disease in general. Continuous positive airway pressure treatment has beneficial impacts on CVD risk factors and CVD. However, the true impact of OSA in patients with T2D remains unclear. The International Diabetes Federation recommended routine screening for OSA in patients with T2D, but two-thirds of diabetes healthcare professionals were unaware of these recommendations. The aim of this review is to attempt to answer the following questions. Is OSA diagnosis and treatment important in patients with T2D and why? What is the relevance of OSA to the practising diabetologist?
\end{abstract}

Br J Diabetes 2016;16:107-113

Key words: obstructive sleep apnoea, type 2 diabetes, hypertension, cardiovascular disease, hyperlipidaemia, quality of life

\section{Introduction}

Obstructive sleep apnoea (OSA) affects $17-26 \%$ of men and 9-28\% of women in population-based epidemiological studies. ${ }^{1}$ It is characterised by upper airway instability during sleep that causes recurrent complete or partial upper airway obstruction resulting in recurrent episodes of either complete (apnoea) or partial (hypopnea) cessation of airflow. ${ }^{2}$ Apnoeas and hypopneas are associated with recurrent oxygen desaturations, cyclical changes in intrathoracic pressure (as the patient attempts to breathe against a blocked airway), increased blood pressure (BP), heart rate and sympathetic activity, and recurrent micro-arousals (due to attempts to open the obstructed airways) that cause sleep fragmentation and disturb the sleep architecture. ${ }^{2}$ The apnoea hypopnea

Institute of Metabolism and Systems, School of Clinical and Experimental Medicine, University of Birmingham, Birmingham; Department of Diabetes and Endocrinology, Birmingham Heartlands Hospital, Birmingham, UK

Address for correspondence: $\mathrm{Dr}$ Abd A Tahrani Department of Diabetes and Endocrinology, Birmingham Heartlands Hospital, Birmingham B9 5SS, UK

E-mail: Abd.tahrani@nhs.net

http://dx.doi.org/10.15277/bjd.2016.088 index (AHI) represents the average number of apnoea and hypopnea episodes/hour during sleep: $\geq 5$ events/hour is consistent with a diagnosis of OSA, 2,3 while AHI cut-offs of 15 and 30 indicate moderate and severe OSA. ${ }^{4}$ Other measures of OSA include the Oxygen Desaturation Index (ODI), the average number of oxygen desaturations/hour of sleep (3\% or $4 \%$ depending on the definition used), the lowest nocturnal oxygen saturations and the time spent with oxygen saturation $<90 \%$. Weight loss and continuous positive airway pressure (CPAP) are the mainstay treatments of OSA. Mandibular advancement devices can also be used in patients with mild OSA or those intolerant to CPAP.

Snoring and witnessed apnoeas are common symptoms of OSA, with snoring reported in $95 \%$ of patients. ${ }^{2}$ Excessive daytime sleepiness (EDS), although associated with OSA, seems to have stronger associations with depression and the metabolic syndrome. ${ }^{2,5}$ Other symptoms such as choking, insomnia, nocturia, sweating, fatigue, morning headache, erectile dysfunction and autonomic symptoms have been reported.2,6 Many of these are also common in type 2 diabetes (T2D) and contribute to the burden of disease. OSA should be considered as a cause of such symptoms in patients with T2D after ruling out hypoglycaemia or hyperglycaemia as CPAP treatment can improve these symptoms.

Obesity is a common risk factor for OSA and T2D, 7 and the prevalence of OSA is high in people with T2D (8.5-85\%, with 23.8$70 \%$ for moderate-to-severe OSA).8-14 This wide range reflects differences in the population examined (primary versus secondary care, ethnicities, gender, obesity, etc), the methods used to diagnose OSA (patients' records, questionnaires, oximetry, portable multi-channel cardiovascular monitoring devices or 'gold standard' polysomnography) and the OSA definitions used (AHI versus ODI, different cut-offs). ${ }^{4,14}$ It is not clear, however, whether the prevalence of OSA in patients with T2D is higher than expected for patients with similar adiposity but without T2D. A recent cross-sectional analysis of the European Sleep Apnea Cohort (ESADA; $n=6,616$ ) suggested that the prevalence of T2D, adjusted for obesity and other potential confounders, increased with worsening OSA: odds ratio (OR) 1.33 (95\% Cl 1.04 to 1.72) for mild OSA, $1.73(95 \% \mathrm{Cl} 1.33$ to 2.25$)$ for moderate OSA and $1.87(95 \%$ $\mathrm{Cl} 1.45$ to 2.42$)$ for severe OSA $(p<0.001) .{ }^{15}$

In 2008 the International Diabetes Federation (IDF) recommended routine screening for OSA in patients with T2D, ${ }^{16}$ but two-thirds of diabetes healthcare professionals were unaware of these recommendations or that the local diabetes guidelines did not incorporate assessment for OSA in those at risk. ${ }^{17}$ Nonetheless, the impact of OSA in patients with T2D, how to screen and the benefits of screening are still unclear. 
The impact of OSA on glucose metabolism and pre-diabetes and the consequences of having OSA in general population studies has been reviewed elsewhere.4,18 The aim of this article is to attempt to answer the following questions: Is OSA diagnosis and treatment important in patients with T2D and why? What is the relevance of OSA to the practising diabetologist?

\section{OSA is a risk factor for T2D}

Many cross-sectional studies in the general population $19-28$ and patients with T2D29,30 showed an association between OSA and insulin resistance, but others did not ${ }^{31-33}$ These conflicting results are partly due to variation in the population examined, sample size (studies that did not show an association were smaller) ${ }^{14}$ or because of variation in EDS, which is associated with insulin resistance. ${ }^{34,35}$ Obesity did not explain fully the association between OSA and insulin resistance; many studies adjusted for obesity measures, OSA was associated with insulin resistance in lean men, and OSA can be caused by conditions other than obesity (e.g. acromegaly).36-38

One longitudinal study showed that OSA, AHI, ODI and minimal nocturnal oxygen saturations were independent predictors of worsening insulin resistance ( $>75$ th percentile of change in HOMA-IR) over an 11-year follow-up period after adjustment for age, baseline body mass index (BMI), hypertension, BMI change over follow-up and CPAP. ${ }^{39}$

The impact of OSA on $\beta$-cell dysfunction in humans is limited. A cross-sectional study showed that OSA was associated with impaired $\beta$-cell function in patients with ${ }^{30}$ or without diabetes. ${ }^{40}$

In addition, OSA is associated with non-alcoholic fatty liver disease (NAFLD) and non-alcoholic steatohepatitis (NASH).27,41

OSA predicts the development of incident T2D independently of age, obesity or other confounders, 39,42-46 and 8 hours/night of CPAP improved post-load glycaemia (oral glucose tolerance test) insulin sensitivity, 24-hour BP and norepinephrine levels in a randomised placebo-controlled trial. ${ }^{47}$ However, this study was conducted in the laboratory environment to ensure the high compliance with CPAP, and the effects of CPAP on the incidence of T2D in uncontrolled settings remains to be determined.

\section{OSA is associated with worse glycaemic control in patients with T2D}

Cross-sectional studies show that OSA is associated with poorer glycaemic control, despite adjustments for age, sex, race, BMI, number of medications, exercise, diabetes duration and total sleep time. ${ }^{15,48-50}$ Lower nocturnal oxygen saturations were associated with higher $\mathrm{HbA}_{1 c}$ values in one study, ${ }^{11}$ but elsewhere there was no association between OSA and $\mathrm{HbA}_{1 c_{1}}{ }^{52}$ probably because only $22 \%$ of participants had full polysomnography and the duration of the sleep study was just 4 hours. ${ }^{53}$ Prospective studies assessing the impact of OSA on glycaemic measures longitudinally in patients with $\mathrm{T} 2 \mathrm{D}$ are lacking.

\section{OSA is associated with hypertension}

Extensive epidemiological studies and interventional trials in the general population, but only limited data in patients with $T 2 \mathrm{D}$, have associated OSA with hypertension and non-dipping BP.4,14,18 The
Wisconsin Sleep Cohort Study found adjusted ORs for incident hypertension between 1.42 and 2.89 with increasing $\mathrm{AHI}$ (versus $\mathrm{AHI}=0$ at baseline, $\mathrm{p}=0002$ for the trend). ${ }^{54}$ Long-term ( 7 years) mild and moderate OSA (versus $\mathrm{AHI}<5$ ) increased the risk of incident nocturnal non-dipping BP about threefold and fourfold, respectively, in a subgroup of patients. ${ }^{55} \mathrm{~A}$ large cross-sectional study showed that OSA was more prevalent in T2D patients with awake BP $\geq 135 / 85 \mathrm{mmHg}$ or asleep $B P \geq 120 / 70 \mathrm{mmHg}$ compared with lower $\mathrm{BP}^{56}$ suggesting a link between OSA and hypertension in T2D.

\section{OSA is associated with hyperlipidaemia}

A mechanistic link between OSA and hyperlipidaemia is plausible as chronic intermittent hypoxia could lead to the generation of stearoyl-coenzyme A desaturase-1, oxidative stress, peroxidation of lipids and sympathetic activation. ${ }^{57}$ However, cross-sectional studies were not consistent mainly due to differences in the population examined, study designs and the impact of CPAP. ${ }^{57,58} \mathrm{~A}$ meta-analysis of 64 studies showed that OSA was associated with higher total cholesterol, higher low-density lipoprotein (LDL), higher triglycerides and lower high-density lipoprotein (HDL), while AHI correlated positively with triglycerides and negatively with HDL levels only.58 The association between OSA/AHI and triglycerides is obesity independent. ${ }^{59}$ Longitudinal studies are lacking.

\section{OSA is associated with cardiovascular disease}

General population

OSA has been associated with a larger atherosclerotic plaque volume, with AHI correlating positively with plaque volume. ${ }^{60,61}$ OSA increased the risk of acute myocardial infarction overnight, supporting a role for nocturnal OSA events in the development of cardiovascular disease (CVD). ${ }^{62}$ Prospective observational studies (3-10 years of follow-up) have shown that OSA predicts the development of incident CVD, with adjusted OR/HR for incident CVD of 1.97-4.9.63-68

Age and gender may modulate the relationship between OSA and incident CVD, as suggested by observational cohort studies in which OSA predicted incident coronary artery disease (CAD) only in men aged $<70$ years and predicted heart failure only in men, ${ }^{68}$ or was associated with stroke incidence only in men. ${ }^{69}$ However, a study that included women showed that untreated OSA predicted a combined outcome of incident stroke and $C A D$, driven only by increased risk of stroke. ${ }^{70}$

\section{Patients with T2D}

AHI was associated with a history of stroke (adjusted OR 2.57, 95\% Cl 1.03 to 6.42 ) but not with CAD in a cross-sectional analysis from the Look AHEAD study. ${ }^{71}$ A prospective observational study of 132 consecutive asymptomatic patients with $T 2 D$ and OSA showed that OSA was associated with incident CAD (adjusted HR 2.2, 95\% Cl 1.2 to $3.9, p=0.01$ ) and heart failure (adjusted HR 3.5, 95\% Cl 1.4 to 9.0; $p<0.01$ ) over a median follow-up of 4.9 years. ${ }^{72}$

\section{OSA is associated with diabetes-related microvascular complications}

The link between OSA and microvascular complications is plausible. 
Intermittent hypoxaemia can result in increased oxidative and nitrosative stress, poly-(ADP-ribose) polymerase activation, increased advanced glycation end products, protein kinase $\mathrm{C}$ activation and inflammation in patients with and without diabetes - all of which can result in endothelial dysfunction and microvascular disease. 4,11,14

\section{OSA and diabetic retinopathy}

In Japanese patients undergoing vitreous surgery for advanced diabetic retinopathy (DR), lower oxygen saturations were associated with proliferative DR after adjustment for age, $\mathrm{HbA}_{1 \mathrm{c}}$ and hypertension. ${ }^{73}$ Cross-sectional data from the UK suggest that OSA may be independently associated with DR and maculopathy. ${ }^{74,75}$ Longitudinally, patients with OSA were more likely to develop pre-proliferative/proliferative DR than those with T2D. ${ }^{75}$

\section{OSA and diabetic nephropathy}

In a cross-sectional study of Japanese patients with T2D, ODI $\geq 5$ was independently associated with microalbuminuria in women but not in men after adjustment for confounders. ${ }^{76}$ In another cross-sectional study, OSA was associated with diabetic nephropathy in patients with T2D (adjusted OR 2.64, 95\% CI 1.13 to $6.16, p=0.02) .{ }^{77}$ Longitudinally, the decline in the estimated glomerular filtration rate (eGFR) was greater in patients with OSA than in those without ( $p=0.003)$. OSA was an independent predictor of study end eGFR and eGFR decline.

\section{OSA and diabetic neuropathy}

A cross-sectional study found that patients with OSA were more likely to have diabetic neuropathy $(\mathrm{OR} 2.82,95 \% \mathrm{Cl} 1.44$ to 5.52) and foot insensitivity (OR 3.97, 95\% Cl 1.80 to 8.74) than those without OSA. ${ }^{11}$ OSA has also been shown to be associated with higher prevalence of foot ulceration and lower intra-epidermal nerve fibre density on skin biopsies. ${ }^{78}$

\section{OSA is associated with impaired quality of life}

Several cross-sectional studies showed that OSA, its severity and nocturnal hypoxaemia were associated with worse quality of life

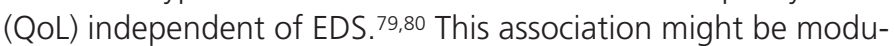
lated by age. ${ }^{79}$

\section{OSA is associated with increased risk of road traffic accidents}

There is extensive evidence using driving stimulators and insurance databases showing an association between OSA and road traffic accidents (RTA) and that CPAP treatment lowers the risk of RTA in patients with OSA. ${ }^{1,81-83}$ T2D is also associated with an increased risk of RTA, but whether having both conditions increases the risk of RTA more than either one alone is unknown.

\section{OSA is associated with erectile dysfunction}

OSA and erectile dysfunction (ED) share many risk factors and their severity often goes in parallel. ${ }^{84}$ In one randomised controlled trial $(R C T)(n=27), 1$ month of CPAP improved ED, but the findings are difficult to interpret as the control group in this study received no treatment rather than sham CPAP; also, the study was unblended and its outcome was self-reported. 85 Other uncontrolled/observational studies suggested beneficial effects of CPAP on ED, and RCTs showed that sildenafil was superior to CPAP for managing ED. ${ }^{84,86-88}$

Impact of CPAP on glucose metabolism, CVD and QoL CPAP improved insulin sensitivity in patients with and without T2D in non-randomised trials ${ }^{89,90}$ and in meta-analyses, ${ }^{89,91,92}$ especially for patients using CPAP $>4$ hours/night. ${ }^{93}$ Uncontrolled studies in patients with T2D89,94-97 showed that CPAP improves postprandial hyperglycaemia, ${ }^{94}$ glycaemic variability ${ }^{95}$ and/or $\mathrm{HbA}_{1 \mathrm{c}}{ }^{94,98}$ However, RCTs examining the impact of CPAP on glycaemic measures are limited and showed conflicting results. One RCT showed no impact of 3 months of CPAP on HbA1c. ${ }^{99}$ This may have been due to true lack of effect, the sample size, the relatively short duration of treatment and issues with CPAP compliance (3.6 hours/night). Another RCT of CPAP vs. usual care in patients with Type 2 diabetes and moderate-severe OSA showed that CPAP had no effect on glycaemic control, but the glycaemic measures were relatively well-controlled at baseline before randomisation. ${ }^{100}$ However, another RCT of 50 patients with T2D and OSA showed that 6 months of CPAP resulted in greater reduction in $\mathrm{HbA}_{1 \mathrm{c}}$ and insulin resistance compared to the control group. ${ }^{101}$ Meta-analyses showed that CPAP did not significantly improve $\mathrm{HbA}_{1 \mathrm{c}}$ in patients with $\mathrm{T} 2 \mathrm{D}$, but these meta-analyses did not include the latest studies described above..$^{92,102}$ As the association between OSA and $\mathrm{HbA}_{1 \mathrm{c}}$ seems stronger during rapid eye movement (REM) sleep, ${ }^{103}$ CPAP might have more impact on $\mathrm{HbA}_{1 \mathrm{c}}$ at this sleep stage; CPAP use of $>4$ hours/night may be required to improve $\mathrm{HbA}_{1 \mathrm{c}}$ as REM occurs predominantly towards the end of the night. CPAP therefore cannot be recommended to improve glycaemic control in T2D and well-designed RCTs are needed. ${ }^{104}$

CPAP lowered BP in hypertensive patients with OSA in several RCTs and meta-analyses ${ }^{105-107}$ and resulted in nocturnal dipping in BP in patients with resistant hypertension. 107 However, valsartan was superior to CPAP (difference in mean 24-hour BP $-7.0 \mathrm{mmHg}, 95 \% \mathrm{Cl}-10.9$ to $-3.1, \mathrm{p}<0.001$ ) in an 8-week randomised crossover study. ${ }^{108}$ CPAP was associated with a mean BP change of $-6.81 /-3.69 \mathrm{mmHg}$ over 9-12 months in a retrospective cohort database study of patients with newly diagnosed OSA and pre-existing hypertension or T2D. 109 CPAP lowered systolic and diastolic BP $(149 / 80 \mathrm{mmHg}$ to $140 / 73 \mathrm{mmHg}$, $\mathrm{p}=0.005 / 0.007$ ) in another randomised trial. ${ }^{97}$ As yet, the impact of CPAP on incident hypertension is unclear. ${ }^{110}$

CPAP reduced total and LDL cholesterol and increased HDL cholesterol but had no effect on triglycerides in a meta-analysis of 29 trials. ${ }^{111}$ Another meta-analysis including only RCTs $(n=6)$ showed that CPAP reduced total cholesterol (particularly in younger more obese patients and those who used CPAP for a longer period) without effects on other lipid parameters. ${ }^{112}$ Three months of CPAP had no effect on lipids in a RCT in patients with T2D, but lipids were well controlled at baseline. ${ }^{97}$ Overall, the impact of CPAP on lipids might be less relevant than that of lipidlowering treatments. 
CPAP was associated with a lower CVD incidence compared with no CPAP in some observational studies. ${ }^{63,64}$ Randomisation of 723 patients with $A H I \geq 20$ and Epworth sleepiness score $\leq 10$ to CPAP versus no CPAP for 4 years had no impact on the incidence of a composite of hypertension and CVD (OR 0.83, 95\% $\mathrm{Cl} 0.63$ to $1.1 ; p=0.20$ ). ${ }^{110}$ However, the combined outcome (but not CVD alone, perhaps due to a lack of events) was reduced in those who used CPAP $\geq 4$ hours/night (OR $0.72,95 \% \mathrm{Cl} 0.52$ to $0.98 ; p=0.04)$. The impact of CPAP on CVD in patients with T2D remains unknown. On the one hand, the favourable impact of CPAP on CVD risk factors suggests that CPAP might lower CVD but, as the impact of CPAP on CVD risk factors may not be greater than currently available treatments, then CPAP might not have an additional benefit. RCTs are again needed to answer this question.

The impact of CPAP on microvascular complications in patient with T2D is limited to a small number of observational studies. In a cohort study from the UK, patients who were more compliant with CPAP had a lower progression of DR. ${ }^{75}$ CPAP may support improved functionality rather than actual change in macular oedema. ${ }^{112} \mathrm{~A} \mathrm{RCT}$ assessing the impact of CPAP on maculopathy is currently ongoing. ${ }^{113}$ CPAP was also associated with less eGFR decline in an observational study from the UK. ${ }^{77}$

Uncontrolled studies suggest that 2-6 months of CPAP might improve vitality, social functioning, mental health, physical health and levels of independence, with the magnitude of improvement related to the baseline QoL impairment rather than OSA severity.80,114 However, another study found that the improvement in QoL on CPAP was similar irrespective of compliance. ${ }^{115}$ Data in T2D are lacking.

\section{Conclusions}

OSA is very common in patients with T2D and is associated with impaired QoL, ED, CV risk factors, CVD and microvascular complications in patients with and without T2D. However, convincing evidence from RCTs in patients with T2D that CPAP treatment has a favourable impact on CVD, microvascular complications or QoL are still lacking. Evidence from general populations suggests that CPAP improves hypertension, hyperlipidaemia, insulin resistance, QoL and CVD. In addition, OSA symptoms are common in patients with T2D and CPAP will improve these symptoms.

Most diabetologists do not check for OSA in patients with $T 2 D$, despite its high prevalence in this population and despite a recommendation to do so by the IDF since 2008. This is further complicated by a lack of consensus regarding the best way to screen for OSA in patients with T2D and the lack of data regarding the impact of CPAP and cost-effectiveness, which raises further challenges for diabetologists. However, regardless of the impact of CPAP on diabetes-related outcomes, it is important to remember that OSA lowers the risk of RTA. In addition, diabetologists should be vigilant to diagnose OSA in patients with T2D in whom CPAP might have a favourable impact, such as patients with OSA-related symptoms or those with resistant hypertension or significant insulin resistance. Ongoing RCTs will clarify the impact of CPAP on diabetes-related outcomes, particularly gly-

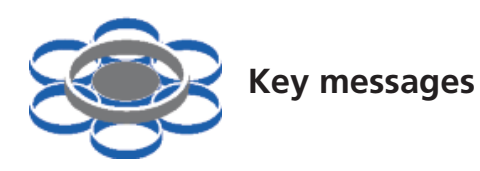

- Obstructive sleep apnoea (OSA) is common in both the general population and in those with type 2 diabetes, with an association with obesity

- The International Diabetes Federation recommends screening patients with type 2 diabetes for OSA, but practice varies and there is no consensus approach

- Continuous positive airway pressure treatment has an impact on blood pressure, cholesterol, insulin resistance, quality of life and possibly cardiovascular disease, but the evidence in patients with type 2 diabetes is limited

caemic control and microvascular and macrovascular disease. In addition, several studies are examining the role of a number of biomarkers to aid screening for OSA in patients with T2D.

\section{Conflict of interest None.}

Disclosure The author is a clinician scientist supported by the National Institute for Health Research (NIHR) in the UK. The views expressed in this publication are those of the author and not necessarily those of the National Health Service, the NIHR or the Department of Health.

Funding No funding was received for the publication of this article.

\section{References}

1. Young T, Peppard PE, Gottlieb DJ. Epidemiology of obstructive sleep apnea: a population health perspective. Am J Respir Crit Care Med 2002;165:1217-39.

2. McNicholas WT. Diagnosis of obstructive sleep apnea in adults. Proc Am Thoracic Soc 2008;5:154-60.

http://dx.doi.org/10.1513/pats.200708-118MG

3. Epstein LJ, Kristo D, Strollo PJ Jr, et al. Clinical guideline for the evaluation, management and long-term care of obstructive sleep apnea in adults. J Clin Sleep Med 2009:5:263-76.

4. Tahrani AA. Diabetes and sleep apnea. International Textbook of Diabetes Mellitus. John Wiley \& Sons, 2015, 316-36.

5. Bixler EO, Vgontzas AN, Lin HM, Calhoun SL, Vela-Bueno A, Kales A. Excessive daytime sleepiness in a general population sample: the role of sleep apnea, age, obesity, diabetes, and depression. J Clin Endocrinol Metab 2005;90:4510-15.

6. Martin SA, Atlantis E, Lange K, et al. Predictors of sexual dysfunction incidence and remission in men. J Sex Med 2014;11:1136-47. http://dx.doi.org/10.1111/jsm. 12483

7. Punjabi NM. The epidemiology of adult obstructive sleep apnea. Proc Am Thorac Soc 2008;5:136-43.

http://dx.doi.org/10.1513/pats.200709-155MG

8. West SD, Nicoll DJ, Stradling JR. Prevalence of obstructive sleep apnoea in men with type 2 diabetes. Thorax 2006;61:945-50.

9. Foster GD, Sanders MH, Millman R, et al. Obstructive sleep apnea among obese patients with type 2 diabetes. Diabetes Care 2009; 32:1017-19. http://dx.doi.org/10.2337/dc08-1776

10. Lam DCL, Lui MMS, Lam JCM, Ong LHY, Lam KSL, Ip MSM. Prevalence and recognition of obstructive sleep apnea in Chinese patients with type 2 diabetes mellitus. Chest 2010;138:1101-07. http://dx.doi.org/10.1378/chest.10-0596

11. Tahrani AA, Ali A, Raymond NT, et al. Obstructive sleep apnea and diabetic neuropathy: a novel association in patients with type 2 diabetes. Am J Respir Crit Care Med 2012;186:434-41. 
http://dx.doi.org/10.1164/rccm.201112-21350C.

12. Heffner JE, Rozenfeld Y, Kai M, Stephens EA, Brown LK. Prevalence of diagnosed sleep apnea among patients with type 2 diabetes in primary care. Chest 2012:141:1414-21. http://dx.doi.org/10.1378/chest.11-1945

13. Lecomte P, Criniere L, Fagot-Campagna A, Druet C, Fuhrman C. Underdiagnosis of obstructive sleep apnoea syndrome in patients with type 2 diabetes in France: ENTRED 2007. Diabetes Metab 2013;39:139-47. http://dx.doi.org/10.1016/j.diabet.2012.10.004

14. Tahrani AA, Ali A, Stevens MJ. Obstructive sleep apnoea and diabetes: an update. Curr Opin Pulm Med 2013;19:631-8. http://dx.doi.org/10.1097/MCP.0b013e3283659da5

15. Kent BD, Grote L, Ryan S, et al. Diabetes mellitus prevalence and control in sleep-disordered breathing: the European Sleep Apnea cohort (ESADA) study. Chest 2014;146:982-90.

http://dx.doi.org/10.1378/chest.13-2403

16. Shaw JE, Punjabi NM, Wilding JP, Alberti KG, Zimmet PZ. Sleep-disordered breathing and type 2 diabetes: a report from the International Diabetes Federation Taskforce on Epidemiology and Prevention. Diabetes Res Clin Pract 2008;81:2-12. http://dx.doi.org/10.1016/j.diabres.2008.04.025

17. Seetho IW, O'Brien SV, Hardy KJ, Wilding JP. Obstructive sleep apnoea in diabetes: assessment and awareness. $\mathrm{Br} J$ Diabetes Vasc Dis 2014;14:105-08. http://dx.doi.org/10.15277/bjdvd.2014.025

18. Tahrani AA, Ali A. Obstructive sleep apnoea and type 2 diabetes. Eur Endocrinol 2014; 10:43-50

19. Grunstein RR, Stenlof K, Hedner J, Sjostrom L. Impact of obstructive sleep apnea and sleepiness on metabolic and cardiovascular risk factors in the Swedish Obese Subjects (SOS) Study. Int J Obes Relat Metab Disord 1995;19:410-18.

20. Vgontzas AN, Papanicolaou DA, Bixler EO, et al. Sleep apnea and daytime sleepiness and fatigue: relation to visceral obesity, insulin resistance, and hypercytokinemia. J Clin Endocrinol Metab 2000;85:1151-8.

21. Ip MSM, Lam BING, Ng MMT, Lam WK, Tsang KWT, Lam KSL. Obstructive sleep apnea is independently associated with insulin resistance. Am J Respir Crit Care Med 2002:165:670-6.

22. Punjabi NM, Sorkin JD, Katzel LI, Goldberg AP, Schwartz AR, Smith PL. Sleep-disordered breathing and insulin resistance in middle-aged and overweight men. Am J Respir Crit Care Med 2002;165:677-82.

23. Barcelo A, Barbe F, Llompart E, et al. Effects of obesity on C-reactive protein level and metabolic disturbances in male patients with obstructive sleep apnea. Am J Med 2004;117:118-21.

24. Punjabi NM, Shahar E, Redline S, Gottlieb DJ, Givelber R, Resnick HE. Sleep-disordered breathing, glucose intolerance, and insulin resistance: The Sleep Heart Health Study. Am J Epidemiol 2004;160:521-30.

25. Makino S, Handa H, Suzukawa K, et al. Obstructive sleep apnoea syndrome, plasma adiponectin levels, and insulin resistance. Clin Endocrinol (Oxf) 2006:64:12-19.

26. Punjabi NM, Beamer BA. Alterations in glucose disposal in sleep-disordered breathing. Am J Respir Crit Care Med 2009;179:235-40. http://dx.doi.org/10.1164/rccm.200809-13920C

27. Polotsky VY, Patil SP, Savransky V, et al. Obstructive sleep apnea, insulin resistance, and steatohepatitis in severe obesity. Am J Respir Crit Care Med 2009;179:228-34. http://dx.doi.org/10.1164/rccm.200804-6080C

28. Bhushan B, Misra A, Guleria R. Obstructive sleep apnea is independently associated with the metabolic syndrome in obese Asian Indians in northern India. Metab Syndr Relat Disord 2010;8:431-5.

29. Hermans MP, Ahn SA, Rousseau MF. Cardiometabolic phenotype and UKPDS risk in male type 2 diabetic patients with obstructive sleep apnoea. Diabetes \& Metabolic Syndrome: Clinical Research \& Reviews 2009:3:50-4.

30. Hermans MP, Ahn SA, Mahadeb YP, Rousseau MF. Sleep apnoea syndrome and 10-year cardiovascular risk in females with type 2 diabetes: relationship with insulin secretion and insulin resistance. Diabetes Metab Res Rev 2013;29:227-34. http://dx.doi.org/10.1002/dmrr.2387

31. Gruber A, Horwood F, Sithole J, Ali NJ, Idris I. Obstructive sleep apnoea is independently associated with the metabolic syndrome but not insulin resistance state. Cardiovasc Diabetol 2006;5:22.

32. Sharma SK, Kumpawat S, Goel A, Banga A, Ramakrishnan L, Chaturvedi P. Obesity, and not obstructive sleep apnea, is responsible for metabolic abnormalities in a cohort with sleep-disordered breathing. Sleep Med 2007:8:12-17.

33. Onat A, Hergenc $G$, Uyarel $H$, et al. Obstructive sleep apnea syndrome is associated with metabolic syndrome rather than insulin resistance. Sleep Breath 2007;11:23-30.

34. Barcelo $A$, Barbe $F$, de la Pena $M$, et al. Insulin resistance and daytime sleepiness in patients with sleep apnoea. Thorax 2008;63:946-50. http://dx.doi.org/10.1136/thx.2007.093740

35. Nena E, Steiropoulos P, Papanas N, et al. Sleepiness as a marker of glucose deregulation in obstructive sleep apnea. Sleep Breath 2012;16:181-6. http://dx.doi.org/10.1007/s11325-010-0472-y

36. Pamidi S, Wroblewski K, Broussard J, et al. Obstructive sleep apnea in young lean men: impact on insulin sensitivity and secretion. Diabetes Care 2012;35:2384-9. http://dx.doi.org/10.2337/dc12-0841

37. Lin QC, Zhang XB, Chen GP, Huang DY, Din HB, Tang AZ. Obstructive sleep apnea syndrome is associated with some components of metabolic syndrome in nonobese adults. Sleep Breath 2012;16:571-8. http://dx.doi.org/10.1007/s11325-011-0544-7

38. Duarte FH, Jallad RS, Amaro AC, Drager LF, Lorenzi-Filho G, Bronstein MD. The impact of sleep apnea treatment on carbohydrate metabolism in patients with acromegaly. Pituitary 2012;16:341-50. http://dx.doi.org/ 10.1007/s11102-012-0430-8

39. Lindberg E, Theorell-Haglöw J, Svensson M, Gislason T, Berne C, Janson C. Sleep apnea and glucose metabolism: a long-term follow-up in a community-based sample. Chest 2012;142:935-42.

40. Punjabi NM, Beamer BA. Alterations in glucose disposal in sleep-disordered breathing. Am J Respir Crit Care Med 2009;179:235-40. http://dx.doi.org/10.1164/rccm.200809-13920C

41. Mishra P, Nugent C, Afendy A, et al. Apnoeic-hypopnoeic episodes during obstructive sleep apnoea are associated with histological nonalcoholic steatohepatitis. Liver Int 2008:28:1080-6.

42. Elmasry A, Janson C, Lindberg E, Gislason T, Tageldin MA, Boman G. The role of habitual snoring and obesity in the development of diabetes: a 10-year follow-up study in a male population. J Intern Med 2000; 248:13-20.

43. Reichmuth KJ, Austin D, Skatrud JB, Young T. Association of sleep apnea and type II diabetes: a population-based study. Am J Respir Crit Care Med 2005;172:1590-5.

44. Botros N, Concato J, Mohsenin V, Selim B, Doctor K, Yaggi HK. Obstructive sleep apnea as a risk factor for type 2 diabetes. Am J Med 2009;122:1122-7. http://dx.doi.org/10.1016/j.amjmed.2009.04.026

45. Celen YT, Hedner J, Carlson J, Peker Y. Impact of gender on incident diabetes mellitus in obstructive sleep apnea: a 16-year follow-up. J Clin Sleep Med 2010;6:244-50.

46. Wang $X, B i$ Y, Zhang Q, Pan F. Obstructive sleep apnoea and the risk of type 2 diabetes: a meta-analysis of prospective cohort studies. Respirology 2013;18:140-6. http://dx.doi.org/10.1111/j.1440-1843. 2012.02267.x

47. Pamidi S, Wroblewski K, Stepien M, et al. Eight hours of nightly CPAP treatment of obstructive sleep apnea improves glucose metabolism in prediabetes: a randomized controlled trial. Am J Respir Crit Care Med 2015;192:96-105. http://dx.doi.org/10.1164/rccm.201408-1564OC

48. Papanas N, Steiropoulos P, Nena E, et al. HbA1C is associated with severity of obstructive sleep apnea hypopnea syndrome in nondiabetic men. Vasc Health Risk Manag 2009;5:751-6.

49. Pillai A, Warren G, Gunathilake W, Idris I. Effects of sleep apnea severity on glycemic control in patients with type 2 diabetes prior to continuous positive airway pressure treatment. Diabetes Technol Ther 2011;13:9459.

50. Aronsohn RS, Whitmore H, Van Cauter E, Tasali E. Impact of untreated obstructive sleep apnea on glucose control in type 2 diabetes. Am J Respir Crit Care Med 2010;181:507-13. http://dx.doi.org/10.1164/rccm.200909-14230C

51. Tamura A, Kawano Y, Watanabe T, Kadota J. Obstructive sleep apnea increases hemoglobin $\mathrm{A} 1 \mathrm{c}$ levels regardless of glucose tolerance status. Sleep Med 2012;13:1050-5. http://dx.doi.org/10.1016/j.sleep.2012.04.007

52. Einhorn D, Stewart DA, Erman MK, Gordon N, Philis-Tsimikas A, Casal E. Prevalence of sleep apnea in a population of adults with type 2 diabetes mellitus. Endocr Pract 2007;13:355-62. 
53. Pamidi S, Tasali E. Obstructive sleep apnea and type 2 diabetes: is there a link? Frontiers Neurol 2012;3:126.

54. Peppard PE, Young T, Palta M, Skatrud J. Prospective study of the association between sleep-disordered breathing and hypertension. $N$ Engl $J$ Med 2000;342:1378-84

55. Hla KM, Young T, Finn L, Peppard PE, Szklo-Coxe M, Stubbs M. Longitudinal association of sleep-disordered breathing and nondipping of nocturnal blood pressure in the Wisconsin Sleep Cohort Study. Sleep 2008;31:795-800

56. Ayala DE, Moyá A, Crespo JJ, et al. Circadian pattern of ambulatory blood pressure in hypertensive patients with and without type 2 diabetes. Chronobiol Int 2012;30:99-115. http://dx.doi.org/10.3109/07420528.2012.701489

57. Adedayo A, Olafiranye O, Smith D, et al. Obstructive sleep apnea and dyslipidemia: evidence and underlying mechanism. Sleep Breath 2014;18:13-18. http://dx.doi.org/10.1007/s11325-012-0760-9

58. Nadeem R, Singh M, Nida M, et al. Effect of obstructive sleep apnea hypopnea syndrome on lipid profile: a meta-regression analysis. J Clin Sleep Med 2014;10:475-89. http://dx.doi.org/10.5664/jcsm.3690

59. Lin QC, Zhang XB, Chen GP, Huang DY, Din HB, Tang AZ. Obstructive sleep apnea syndrome is associated with some components of metabolic syndrome in nonobese adults. Sleep Breath 2012;16:571-8. http://dx.doi.org/10.1007/s11325-011-0544-7

60. Turmel J, Sériès F, Boulet LP, et al. Relationship between atherosclerosis and the sleep apnea syndrome: an intravascular ultrasound study. Int $J$ Cardiol 2009; 132:203-09.

61. Kent BD, Garvey JF, Ryan S, Nolan G, Dodd JD, McNicholas WT. Severity of obstructive sleep apnoea predicts coronary artery plaque burden: a coronary CT angiography study. Eur Respir J 2013:42:1263-70. http://dx.doi.org/10.1183/09031936.00094812

62. Kuniyoshi FH, Garcia-Touchard A, Gami AS, et al. Day-night variation of acute myocardial infarction in obstructive sleep apnea. J Am Coll Cardiol 2008;52:343-6. http://dx.doi.org/10.1016/j.jacc.2008.04.027

63. Peker Y, Hedner J, Norum J, Kraiczi H, Carlson J. Increased incidence of cardiovascular disease in middle-aged men with obstructive sleep apnea: a 7-year follow-up. Am J Respir Crit Care Med 2002;166:159-65.

64. Marin JM, Carrizo SJ, Vicente E, Agusti AG. Long-term cardiovascular outcomes in men with obstructive sleep apnoea-hypopnoea with or without treatment with continuous positive airway pressure: an observational study. The Lancet 2005:365:1046-53.

65. Yaggi HK, Concato J, Kernan WN, Lichtman JH, Brass LM, Mohsenin V. Obstructive sleep apnea as a risk factor for stroke and death. $N$ Engl $J$ Med 2005;353:2034-41.

66. Ou Q, Chen YC, Zhuo SQ, et al. Continuous positive airway pressure treatment reduces mortality in elderly patients with moderate to severe obstructive severe sleep apnea: a cohort study. PLOS One 2015; 10:e0127775. http://dx.doi.org/10.1371/journal.pone.0127775

67. Molnar MZ, Mucsi I, Novak M, et al. Association of incident obstructive sleep apnoea with outcomes in a large cohort of US veterans. Thorax 2015;70:888-95. http://dx.doi.org/10.1136/thoraxjnl-2015-206970

68. Gottlieb DJ, Yenokyan G, Newman AB, et al. Prospective study of obstructive sleep apnea and incident coronary heart disease and heart failure: The Sleep Heart Health Study. Circulation 2010;122:352-60. http://dx.doi.org/10.1161/CIRCULATIONAHA.109.901801

69. Redline S, Yenokyan G, Gottlieb DJ, et al. Obstructive sleep apneahypopnea and incident stroke. Am J Respir Crit Care Med 2010;182: 269-77. http://dx.doi.org/10.1164/rccm.200911-1746OC

70. Campos-Rodriguez F, Martinez-Garcia MA, Reyes-Nuñez N, CaballeroMartinez I, Catalan-Serra P, Almeida-Gonzalez CV. Role of sleep apnea and continuous positive airway pressure therapy in the incidence of stroke or coronary heart disease in women. Am J Respir Crit Care Med 2014;189:1544-50. http://dx.doi.org/10.1164/rccm.201311-20120C

71. Rice TB, Foster GD, Sanders MH, et al. The relationship between obstructive sleep apnea and self-reported stroke or coronary heart disease in overweight and obese adults with type 2 diabetes mellitus. Sleep 2012;35:1293-8.

72. Seicean S, Strohl KP, Seicean A, Gibby C, Marwick TH. Sleep disordered breathing as a risk of cardiac events in subjects with diabetes mellitus and normal exercise echocardiographic findings. Am J Cardiol 2013;111:1214-20. http://dx.doi.org/10.1016/j.amjcard.2012.12.053
73. Shiba T, Maeno T, Saishin Y, Hori Y, Takahashi M. Nocturnal intermittent serious hypoxia and reoxygenation in proliferative diabetic retinopathy cases. Am J Ophthalmol 2010;149:959-63. http://dx.doi.org/10.1016/j.ajo.2010.01.006

74. West SD, Groves DC, Lipinski HJ, et al. The prevalence of retinopathy in men with type 2 diabetes and obstructive sleep apnoea. Diabet Med 2010;27:423-30. http://dx.doi.org/10.1111/j.1464-5491.2010.02962.x

75. Tahrani AA, Dodson P, Ali A, et al. Obstructive sleep apnoea is associated with sight threatening retinopathy and predicts the development of preproliferative and proliferative retinopathy in patients with type 2 diabetes: a longitudinal analysis. Eur J Ophthalmol 2013;23:449.

76. Furukawa S, Saito I, Yamamoto S, et al. Nocturnal intermittent hypoxia as an associated risk factor for microalbuminuria in Japanese patients with type 2 diabetes mellitus. Eur J Endocrinol 2013;169:239-46. http://dx.doi.org/10.1530/EJE-13-0086

77. Tahrani AA, Ali A, Raymond NT, et al. Obstructive sleep apnea and diabetic nephropathy: a cohort study. Diabetes Care 2013;36:3718-25. http://dx.doi.org/10.2337/dc13-0450

78. Altaf QA, Ali A, Piya MK, Raymond NT, Tahrani AA. The relationship between obstructive sleep apnea and intra-epidermal nerve fiber density, PARP activation and foot ulceration in patients with type 2 diabetes J Diabetes Complications 2016;30(7):1315-20. http://dx.doi.org/10.1016/j.jdiacomp.2016.05.025.

79. Appleton S, Vakulin A, McEvoy RD, et al. Undiagnosed obstructive sleep apnea is independently associated with reductions in quality of life in middle-aged, but not elderly men of a population cohort. Sleep Breath 2015;19:1309-16. http://dx.doi.org/10.1007/s11325-015-1171-5

80. D'Ambrosio C, Bowman T, Mohsenin V. Quality of life in patients with obstructive sleep apnea: effect of nasal continuous positive airway pressureGÇöa prospective study. Chest 1999;115:123-9.

81. Horne JA, Reyner LA. Sleep related vehicle accidents. BMJ 1995;310 565-7.

82. Young T, Blustein J, Finn L, Palta M. Sleep-disordered breathing and motor vehicle accidents in a population-based sample of employed adults. Sleep 1997;20:608-13.

83. Karimi M, Hedner J, Häbel H, Nerman O, Grote L. A sleep apnea-related risk of motor vehicle accidents is reduced by continuous positive airway pressure: Swedish Traffic Accident Registry Data. Sleep 2014;38:341-9. doi: 10.5665/sleep.4486

84. Hoyos CM, Melehan KL, Phillips CL, Grunstein RR, Liu PY. To ED or not to ED: Is erectile dysfunction in obstructive sleep apnea related to endothelial dysfunction? Sleep Med Rev 2015;20:5-14.

http://dx.doi.org/10.1016/j.smrv.2014.03.004

85. Li F, Feng Q, Zhang $X$, Liu Q. [Treatment for erectile dysfunction patients with obstructive sleep apnea syndrome by nasal continual positive airway pressure]. Zhonghua nan ke xue (National Journal of Andrology) 2004;10:355-7.

86. Perimenis $\mathrm{P}$, Karkoulias $\mathrm{K}$, Markou $\mathrm{S}$, et al. Erectile dysfunction in men with obstructive sleep apnea syndrome: a randomized study of the efficacy of sildenafil and continuous positive airway pressure. Int J Impotence Res 2004; 16:256-60.

87. Perimenis $\mathrm{P}$, Karkoulias $\mathrm{K}$, Konstantinopoulos $\mathrm{A}$, et al. Sildenafil versus continuous positive airway pressure for erectile dysfunction in men with obstructive sleep apnea: a comparative study of their efficacy and safety and the patient's satisfaction with treatment. Asian J Androl 2007, 9:259-64.

88. Li X, Dong Z, Wan Y, Wang Z. Sildenafil versus continuous positive airway pressure for erectile dysfunction in men with obstructive sleep apnea: a meta-analysis. The Aging Male 2010;13:82-6.

http://dx.doi.org/10.3109/13685530903406789

89. Harsch IA, Schahin SP, Brückner K, et al. The effect of continuous positive airway pressure treatment on insulin sensitivity in patients with obstructive sleep apnoea syndrome and type 2 diabetes. Respiration 2004;71:252-9.

90. Brooks B, Cistulli PA, Borkman M, et al. Obstructive sleep apnea in obese noninsulin-dependent diabetic patients: effect of continuous positive airway pressure treatment on insulin responsiveness. J Clin Endocrinol Metab 1994;79:1681-5.

91. Iftikhar $\mathrm{IH}$, Hoyos CM, Phillips CL, Magalang UJ. Meta-analyses of the association of sleep apnea with insulin resistance, and the effects of 
CPAP on HOMA-IR, adiponectin, and visceral adipose fat. J Clin Sleep Med 2015;11:475-85. http://dx.doi.org/10.5664/jcsm.4610

92. Chen L, Pei JH, Chen HM. Effects of continuous positive airway pressure treatment on glycaemic control and insulin sensitivity in patients with obstructive sleep apnoea and type 2 diabetes: a meta-analysis. Arch Med Sci 2014;10:637-42. http://dx.doi.org/10.5114/aoms.2014.44854

93. Yang D, Liu Z, Yang H. The impact of effective continuous positive airway pressure on homeostasis model assessment insulin resistance in non-diabetic patients with moderate to severe obstructive sleep apnea. Diabetes Metab Res Rev 2012;28:499-504.

94. Babu AR, Herdegen J, Fogelfeld L, Shott S, Mazzone T. Type 2 diabetes, glycemic control, and continuous positive airway pressure in obstructive sleep apnea. Arch Intern Med 2005; 165:447-52.

95. Pallayova M, Donic V, Tomori Z. Beneficial effects of severe sleep apnea therapy on nocturnal glucose control in persons with type 2 diabetes mellitus. Diabetes Res Clin Pract 2008;81:e8-11. http://dx.doi.org/10.1016/j.diabres.2008.03.012

96. Shpirer I, Rapoport M, Stav D, Elizur A. Normal and elevated HbA1C levels correlate with severity of hypoxemia in patients with obstructive sleep apnea and decrease following CPAP treatment. Sleep Breath 2012;16:461-6. http://dx.doi.org/10.1007/s11325-011-0525-x

97. Myhill PC, Davis WA, Peters KE, Chubb SAP, Hillman D, Davis TME. Effect of continuous positive airway pressure therapy on cardiovascular risk factors in patients with type 2 diabetes and obstructive sleep apnea. $J$ Clin Endocrinol Metab 2012;97:4212-18. http://dx.doi.org/10.1210/jc.2012-2107

98. Hassaballa HA, Tulaimat A, Herdegen JJ, Mokhlesi B. The effect of continuous positive airway pressure on glucose control in diabetic patients with severe obstructive sleep apnea. Sleep Breath 2005;9:176-80.

99. West SD, Nicoll DJ, Wallace TM, Matthews DR, Stradling JR. Effect of CPAP on insulin resistance and $\mathrm{HbA} 1 \mathrm{c}$ in men with obstructive sleep apnoea and type 2 diabetes. Thorax 2007;62:969-74.

100.Shaw JE, Punjabi NM, Naughton MT et al. The effect of treatment of obstructive sleep apnea on glycemic control in type 2 diabetes. Am J Respir Crit Care Med 2016:194(4):486-92. http://dx.doi.org/10.1164/rccm.201511-22600C

101. Martínez-Cerón E, Barquiel B, Bezos AM et al. Effect of continuous positive airway pressure on glycemic control in patients with obstructive sleep apnea and type 2 diabetes. A Randomized Clinical Trial. Am J Respir Crit Care Med 2016;194(4):476-85. http://dx.doi.org/10.1164/rccm.201510-19420C.

102.Feng $Y$, Zhang Z, Dong ZZ. Effects of continuous positive airway pressure therapy on glycaemic control, insulin sensitivity and body mass index in patients with obstructive sleep apnoea and type 2 diabetes: a systematic review and meta-analysis. Npj Primary Care Respir Med 2015;25:15005. http://dx.doi.org/10.1038/npjpcrm.2015.5.

103. Grimaldi D, Beccuti G, Touma C, Van Cauter E, Mokhlesi B. Association of obstructive sleep apnea in REM sleep with reduced glycemic control in type 2 diabetes: therapeutic implications. Diabetes Care 2014;37: 355-63. http://dx.doi.org/10.2337/dc13-0933

104. Tahrani AA. Comment on Guest et al. Clinical outcomes and cost- effectiveness of continuous positive airway pressure to manage obstructive sleep apnea in patients with type 2 diabetes in the U.K. Diabetes Care 2014;37:e200-e201. http://dx.doi.org/10.2337/dc14-1000

105. Hu X, Fan J, Chen S, Yin Y, Zrenner B. The role of continuous positive airway pressure in blood pressure control for patients with obstructive sleep apnea and hypertension: a meta-analysis of randomized controlled trials. J Clin Hypertens 2015;17:215-22. http://dx.doi.org/10.1111/jch.12472

106. Pedrosa RP, Drager LF, de Paula LKG, Amaro ACS, Bortolotto LA, LorenziFilho $G$. Effects of OSA treatment on BP in patients with resistant hypertension: a randomized trial. Chest 2013;144:1487-94. http://dx.doi.org/10.1378/chest.13-0085

107. Martínez-García M, Capote F, Campos-Rodríguez F. Effect of CPAP on blood pressure in patients with obstructive sleep apnea and resistant hypertension: The HIPARCO randomized clinical trial. JAMA 2013;310: 2407-15. http://dx.doi.org/10.1001/jama.2013.281250

108.Pépin JL, Tamisier R, Barone-Rochette G, Launois SH, Lévy P, Baguet JP. Comparison of continuous positive airway pressure and valsartan in hypertensive patients with sleep apnea. Am J Respir Crit Care Med 2010;182:954-60. http://dx.doi.org/10.1164/rccm.200912-18030C

109.Prasad B, Carley DW, Krishnan JA, Weaver TE, Weaver FM. Effects of positive airway pressure treatment on clinical measures of hypertension and type 2 diabetes. J Clin Sleep Med 2012;8:481-7. http://dx.doi.org/10.5664/jcsm.2136

110.Barbé F, Durán-Cantolla J, Sánchez-de-la-Torre M. Effect of continuous positive airway pressure on the incidence of hypertension and cardiovascular events in nonsleepy patients with obstructive sleep apnea: a randomized controlled trial. JAMA 2012;307:2161-8. http://dx.doi.org/10.1001/jama.2012.4366

111. Nadeem $R$, Singh $M$, Nida $M$, et al. Effect of CPAP treatment for obstructive sleep apnea hypopnea syndrome on lipid profile: a meta-regression analysis. J Clin Sleep Med 2014;10:1295-302. http://dx.doi.org/10.5664/jcsm.4282

112.Xu H, Yi H, Guan J, Yin S. Effect of continuous positive airway pressure on lipid profile in patients with obstructive sleep apnea syndrome: a meta-analysis of randomized controlled trials. Atherosclerosis 2014 234:446-53. http://dx. doi.org/10.1016/j.atherosclerosis.2014.03.034

113. Mason RH, Kiire CA, Groves DC, et al. Visual improvement following continuous positive airway pressure therapy in diabetic subjects with clinically significant macular oedema and obstructive sleep apnoea: proof of principle study. Respiration 2012;84:275-82. http://dx.doi.org/10.1159/000334090

114.Diamanti C, Manali E, Ginieri-Coccossis M, et al. Depression, physical activity, energy consumption, and quality of life in OSA patients before and after CPAP treatment. Sleep Breath 2013;17:1159-68. http://dx.doi.org/10.1007/s11325-013-0815-6

115.Bjornsdottir E, Keenan BT, Eysteinsdottir B, et al. Quality of life among untreated sleep apnea patients compared with the general population and changes after treatment with positive airway pressure. J Sleep Res 2015;24:328-38. http://dx.doi.org/10.1111/jsr.12262 